\title{
O (NÃO)LUGAR DA FILOSOFIA BRASILEIRA
}

Benito Eduardo Maeso ${ }^{1}$

\section{Resumo}

O que faz com que seja possível proclamar a existência de uma filosofia autenticamente brasileira? Neste artigo, serão analisadas algumas características do que poderia ser chamado de pensamento nacional, cujo mecanismo de geração seria caracterizado por dois processos: a apropriação e a ressignificação de conjuntos teóricos externos, gerando uma forma de pensar e agir que carregaria em si mesma a contradição entre o arcaico e o moderno, entre o universal e o particular. Esse mecanismo de funcionamento da formação do pensamento brasileiro é desnudado, de maneiras singulares, pelas análises de Paulo Arantes, Bento Prado Junior e Marilena Chauí, entre outros, que acabam por se debruçar sobre a seguinte questão: é possível uma filosofia genuinamente brasileira que possa abdicar de uma relação com a tradição e a história da filosofia ou é exatamente desta relação sui generis que surge a oportunidade de criarmos nossa própria gramática e discurso filosófico? Em outras palavras, que lugar ocupa o pensamento e a produção intelectual na definição do "ser brasileiro"?

Palavras-chave: Filosofia, Brasil, não-pertencimento, arcaico, moderno, ideologia

\section{THE (NON-)PLACE OF BRAZILIAN PHILOSOPHY}

\footnotetext{
Abstract

What makes it possible to proclaim the existence of an authentic Brazilian Philosophy? This article aims to analyze some characteristics of 
a so-called "Brazilian national thinking", a two-way process of appropriation and resignification of foreign theories. As a result, this process leads to a contradiction between archaism and modernity, between the universal and the singularity. The operation mechanism of Brazilian intellectuality is shown by the works of Paulo Arantes, Bento Prado Jr., Marilena Chaui, among others. All these thinkers have a common question: is it possible to produce a genuine philosophy in Brazil setting aside philosophical tradition and history? Or is it exactly from this sui generis relationship that arise the opportunity to create a new grammar and philosophical discourse for our own? What is the place of intellectuality in the making of a "Brazilian way of think"?

Keywords: Philosophy, Brazil, non-belonging, archaic, modernity, ideology

Bento Prado Junior começa um de seus textos mais importantes sobre a filosofia brasileira com uma provocação certeira sobre o "embaraço" causado pela tarefa de falar sobre esse assunto: "Poderíamos definir esta dificuldade em termos aristotélicos: como saber o que é uma coisa, se não sabermos ao certo se ela é?" (PRADO JR, 2001, p.153).

Mais do que um questionamento sobre a existência de um pensamento que possa ser chamado de autenticamente brasileiro (ou seja, a parte que nos caberia nesse latifúndio do pensamento humano), a pergunta de Bento Prado mira em uma metodologia filosófica específica e na suposta existência de uma "visão de mundo" constante que unificaria as questões brasileiras, o que seria paradoxal em relação a um pressuposto de universalidade do pensamento e da temática filosófica, pressuposto que é carinhosamente aceito por parte da comunidade intelectual.

A questão de Prado Junior traz em si outro problema de fundo, a saber: o que definiria uma filosofia como "brasileira"? Uma das tradições desenvolvidas a este respeito aponta que o pensamento brasileiro tem como principal característica ser "fora do lugar", ser uma contradição implícita entre questões formais e de conteúdo. No Brasil, haveria um mal-estar perene como resultado da tentativa de aclimatar tradições de pensamento de origem europeia às particularidades da formação da sociedade brasileira, gerando um ethos caracterizado pela dialética entre o arcaico e o moderno e por uma certa negatividade enquanto sentimento de não-pertencimento ao conjunto social. A sociedade e a cultura brasileiras teriam como característica um tipo de vazio, uma ausência, o país que "ainda não é", perdido em um (não-)lugar entre o Velho e o Novo mundo.

Porém, essa "presença da ausência" carrega uma estranhíssima contradição em seu funcionamento: esta visão não teria dentro de si, de forma implícita, a ideologia de que existe um modelo perfeito de pensamento - europeu, colonial, civilizatório, iluminista, autóctone ou simplesmente estrangeiro - ao qual teríamos a (in)capacidade de nos ajustar? Ou o assim chamado pensamento brasileiro compartilharia 
de características próprias e basilares de nossa sociedade, na qual desencanto e modernidade gerariam um híbrido de características únicas e incomparáveis com as escolas de pensamento que, de certa forma, colonizaram nossa maneira de pensar?

Essa visão é descrita principalmente pelos trabalhos de Roberto Schwarz e Paulo Arantes a partir da análise de Antonio Cândido sobre a formação da literatura no Brasil. O pensamento "tipicamente" brasileiro não seria nem uma reprodução do pensamento da metrópole nem uma criação genuinamente local, mas um estranho híbrido dialético entre estes elementos, a relação entre um país "errado" e uma cultura "viva".

A via de mão dupla entre formação social e cultural, na qual uma influi diretamente na outra, é vista por Schwarz como pressuposto básico para a autonomização da literatura brasileira, por exemplo, com Machado de Assis - não como uma simples simbiose ou conciliação entre tais fatores, mas como um sinal do estranhamento que eles provocam ao operarem juntos. Ou, nas palavras de ARANTES; "como pôde se formar um escritor de verdade em condições tão adversas?" (1997, p. 31).

Sintetizando um processo muito mais complexo, pode-se dizer que o Brasil "atrasado" não está oposto à Europa moderna e capitalista, funcionando com esta em um sistema de retroalimentação, pois a metrópole só é possível como fruto da exploração da colônia. Conforme Dario Negreiros,

Com isso, a reviravolta é completa: civilização e barbárie, antes terras longínquas, não são senão duas fotografias - tiradas por um retratista hábil e velhaco - da mesma paisagem; "atrasado" e "avançado" constituem, afinal, duas faces coevas de um mesmo fenômeno. Enfim, sendo ambas formações distintas de um só processo, a Metrópole não pode mais ser vista como molde que sirva à Colônia, que tampouco pode ser compreendida como matéria informe: extingue-se, pois, a dualidade hilemórfica Forma metropolitana x Matéria informe colonial, tornando-se igualmente impossível sustentar a perspectiva negativa, que nos permitia enxergar o lado de cá do processo, na comparação com o seu modelo europeu, como falta, vazio, enfim, como o que ainda não é. (NEGREIROS, 2018, p.10)

O efeito disso no trabalho do pensamento não poderia ser menos revolucionário: não somos mais periféricos e deslocados, mas donos de posição privilegiada para apontar as contradições do sistema, pois seríamos em essência a manifestação desta contradição. Machado na prosa, Drummond na poesia, a literatura brasileira se desenvolve ao ponto de ter seu próprio "jeito de escrever", ainda que tardio comparado a outros processos de colonização nas Américas. Todavia, o pensamento filosófico brasileiro parece desenvolver contradições que não permitiriam a formação de sua identidade de forma análoga à exposta acima, ainda que a própria história das formações da produção filosófica brasileira seja imbricada com a da literatura. Conforme Bento Prado, 
Se nos voltarmos, com o mesmo espírito, da literatura para a filosofia brasileira, a nossa conclusão será diferente: o seu registro de nascimento ainda não foi lavrado. Há obras, é certo, e nenhuma "escola" filosófica, provavelmente, deixa de estar representada nas "manifestações filosóficas" de nosso país. Sem diminuir o interesse dessas obras - pois há notáveis -, cabe assinalar que resenhá-las não implicaria nenhuma informação para o leitor europeu; sem contar com o fato de que um "panorama" dessa ordem não caberia nos limites de um artigo. Aqui também se faz marxismo, fenomenologia, existencialismo, positivismo etc.: mas, quase sempre, o que se faz é divulgação. (2001, p. 155)

É preciso, também, observar que características presentes na formação daquilo que ingenuamente chamamos de jeito brasileiro de ser trazem obrigatoriamente elementos dos processos de colonização, ocupação e uso de espaço pelo fato de que a formação do que chamamos de Brasil hoje é um processo historicamente recente e definitivamente conflituoso.

A miscigenação étnica, cultural e territorial não foi, nem de longe, o mar de rosas que por vezes parece surgir na leitura de obras clássicas como O Povo Brasileiro, de Darcy Ribeiro, e Raízes do Brasil, de Sérgio Buarque de Hollanda. E tal diferença de interpretações sobre a formação da sociedade brasileira aparece, por conseguinte, na formação e na apropriação dos ideários presentes na sociedade.

Um exemplo estaria na penetração tanto do liberalismo como do pensamento positivista na sociedade brasileira do século XIX. Se na sociedade europeia burguesa valores como o trabalho, a autonomia da pessoa, a universalidade da lei e a produção cultural sedimentavam-se em um quadro de oposição clara ao ethos do Antigo Regime, as condições sociais e históricas em terras brasileiras mostravam-se substancialmente diferentes, numa sociedade calcada, de acordo com Schwarz, no favor, no privilégio das relações e nas exceções à regra.

O pensamento dito liberal importado da Europa torna-se seu oposto: de revolta burguesa contra a fidalguia e a aristocracia europeias, torna-se dístico de pertencimento a esta pretensa elite nas terras tupiniquins ${ }^{2}$. Conforme o autor,

Tal mal não seria circunscrito a uma pretensa elite financeira (rural/escravocrata ou urbana/ agiota) que, ao mimetizar os hábitos europeus, busca se dissociar do fato de ser, na prática, tão "periférica" quanto as classes sociais às quais nutre ódio. A intelectualidade brasileira sofreria de mal parecido se considerarmos a sobrevivência de um discurso no qual existe um subtexto de salvar o povo de si mesmo, como habilmente parodiado no discurso do ditador Diaz em Terra em Transe, de Glauber Rocha: "Aprenderão, aprenderão, hei de fazer desse lugar uma civilização, pela força, pelo amor da força, pela harmonia universal dos infernos" (cfe. AB'SÁ$B E R, 2010$, p.209). A "civilização forçada" - a violência como prática da formação de uma coletividade - aparece tanto na visão ditatorial, carregada do elemento positivista do culto à ordem, como na ideia de que haveria a possibilidade de um resgate de valores humanistas na sociedade brasileira que resistiriam a essa violência (um resgate a ser operado por uma classe de pensadores?). Tal ideia padece, desde a origem, de um caráter messiânico, ou da necessidade de libertar a população de práticas e pensamentos autoritários, pois por si próprio o indivíduo seria incapaz de compreender o horror presente em sua existência. A pergunta, dolorosa 
Aí a novidade: adotadas as ideias e razões europeias, elas podiam servir e muitas vezes serviram de justificação, nominalmente "objetiva", para o momento de arbitrio que é da natureza do favor. Sem prejuízo de existir, o antagonismo se desfaz em fumaça e os incompatíveis saem de mãos dadas. (SCHWARZ, 2000, p.12 itálicos no original)

Outra questão dessa apropriação sui generis das ideias que grassavam nas metrópoles é relacionada à própria pertinência das ideias sequestradas. O positivismo, por exemplo, tornou-se mais uma roupagem de práticas cotidianas do que uma escola de pensamento, visto que passa a dar um ar cientificista às especulações metafísicas tradicionais que imperavam até o período ${ }^{3}$.

A par da subestimação da filosofia, nutriu-se a mentalidade positivista de uma atitude supervalorativa das ciências ditas positivas, destacando-se seu caráter mais enciclopédico que científico. Não trouxe o positivismo ao Brasil qualquer contribuição ponderável ao progresso das ciências. Ele entrou no país não como um método de investigação, mas como uma maneira de pensar que se poderia chamar cientificista, e sobretudo como uma filosofia social, política e religiosa. (LEONÍDIO, 2008, p.3)

Se realmente esse processo de apropriação e ressignificação caracteriza a formação do pensar e da sociedade brasileira, especificamente sobre o pensamento filosófico, a pergunta que move este texto pode ser sintetizada em um dilema: é possível uma filosofia genuinamente brasileira que possa abdicar de uma relação com a tradição e a história da filosofia ou é exatamente desta relação sui generis que surge a oportunidade de criarmos nossa própria gramática e discurso filosófico? Em outras palavras, que lugar ocupa o pensamento e a produção intelectual na definição do "ser brasileiro"?

\section{Problema de formação e de origem}

Nossa incipiente tradição filosófica, se é que podemos chama-la assim, possui um apreço historicista, temperado com os jargões da última moda filosófica e um ecletismo entremeado de prática, conforme Cruz Costa, mas que acaba por resultar em uma identidade causada pela carência. Por não haver exatamente um conjunto de obras filosóficas que comporia uma tradição autônoma, é essa ausência e a exploração de seus limites e particularidades que seria o fundamento dessa tradição negativa, a ausência de uma cultura nacional sendo a base para a interrogação da possibilidade da filosofia própria e o germe daquilo

mas necessária, a ser feita: e se o indivíduo compreende tal horror, mas simplesmente não liga para ele? Essa seria uma pergunta que a filosofia brasileira precisa enfrentar. 
que o pensador brasileiro deve fazer: estabelecer a possibilidade futura da filosofia nacional ${ }^{4}$.

Outra possibilidade, com base na leitura de Álvaro Vieira Pinto, é entender a filosofia no Brasil como a expressão de uma gênese da consciência brasileira: a busca de uma brasilidade que funcionaria como chave de interpretação de nossa realidade, como síntese hegeliana materializada no conceito de nação. Porém, essa abordagem na qual a consciência social materializa-se como nacional acaba por desembocar em uma ideia de finalidade para a consciência, ou torna a filosofia simultaneamente expressão e crítica da realidade nacional.

Ambas as abordagens tem contradições internas severas: a segunda, por sua aderência absurda ao real, acaba por recusar a autonomia da teoria. Filosofia aqui seria, então, a explicação da consciência e do pensamento brasileiro a partir da própria experiência brasileira, algo como um senso comum mais sofisticado. Mais ainda, na visão de PRADO JR,

a própria noção de ideologia se torna ambígua. Ela não mais significa a consciência deformada ou interessada que os indivíduos e os grupos podem ter da realidade social, em virtude de sua própria posição no interior da sociedade: ela significa, também, uma forma de consciência privilegiada, algo como uma subjetividade "boa" ou eficaz. (p. 160-161)

Já a abordagem de Cruz Costa, por seu caráter historicista, padece de um certo finalismo e da premissa da existência a priori de um horizonte ${ }^{5}$ para o brasileiro, seja este o do desenvolvimento, seja o da eterna situação de colônia. A história das ideias no Brasil seria a história de uma mesma experiência, interpretada por uma mesma consciência.

A esta posição, que de certa forma também encontra-se presente na visão schwarzoarantiana do deslocamento ou do atraso das "ideias fora de lugar", é possível contrapor, conforme CHAUí (2014), que tanto a ideia de destino como a de atraso, seja nos planos cultural ou econômico, pressupõem, de forma implícita, a existência ou idealização de

um modelo de sociedade completamente realizado ou desenvolvido, de sorte que a história passa a ser lida como processo de modernização e esta, como progresso e aproximação gradativa

4 Ainda que, cronologicamente, a Escola de Recife e o trabalho de, entre outros, Tobias Barreto, seja anterior à discussão abordada neste trecho, tal escola é caracterizada por uma afirmação da ideia de uma produção filosófica de comentadores mais do que de pensadores. Não custa lembrar que os materiais produzidos pelos pensadores recifenses eram, entre outras particularidades, escritos em alemão. (cfe. CANTO, informação oral). De acordo com LEONÍ$\mathrm{DIO}$, a Escola de Recife também precisa lidar, à sua maneira, com a herança desse positivismo metafísico, ainda que perfilando-se em um campo oposto: a valorização da mestiçagem tipicamente brasileira como fator de diferenciação positiva. Dentre seus postulados, também, a Escola analisou o papel da escravidão e do autoritarismo como componentes fundantes da sociedade brasileira. 
do atrasado rumo ao desenvolvido, isto é, em direção ao modelo completo. (CHAUI, 2014, p.19)

Mas tal modelo seria uma completa ficção. Desta forma, constrói-se um inusitado problema sobre os movimentos de formação do pensamento brasileiro: a tensão entre arcaísmo e modernidade pode tanto limitar o escopo possível para a produção da filosofia brasileira como ser seu leitmotiv, o princípio de funcionamento do pensamento, que lhe granjearia uma posição privilegiada, ou única, de produção.

\section{A jabuticaba da filosofia}

É do estranhamento entre a sociedade escravista e o ideário liberal que a originalidade do pensamento tipicamente brasileiro surgiria, ou das contradições que atravessam a sociedade brasileira. O que é problemático é assumir, ainda que indiretamente, que tais contradições fariam da sociedade brasileira um caso único no mundo. Essa Fenomenologia do Espírito Jabuticabal Brasileiro, da completa singularidade das relações sociais brasileiras e sua incomensurabilidade em relação aos processos sociais e econômicos planetários, é um desdobramento da mesma ideia-motriz de que o caso brasileiro, enquanto sociedade e forma de pensamento e ação, não tem solução. Entender as particularidades da construção do Brasil como impeditivos de sua relação com o mundo, seja de forma positiva ou negativa, é arriscado e limita o escopo de análise possível.

Soluções filosóficas supostamente made in Brazil, em escolas que muitas vezes acabam por negar o caráter de hibridismo do pensamento nacional (ainda em formação) em prol de uma pureza originária e especial, que mostra a incapacidade e ineficácia de todo o gênero humano não-autenticamente originário de uma terra que nem Brasil se chamaria ainda na compreensão de nossas particularidades, andam junto aos que defendem que os fenômenos sociais, econômicos e de pensamento de caráter mundial seriam inaplicáveis aqui, como se o "jeito brasileiro" também impedisse uma compreensão civilizada do país. Ambas as visões seriam estrangeirismos, ao fim e ao cabo, pois nem somos uma cópia daqueles que colonizaram esta terra nem uma herança intocada daqueles que tiveram seu lugar conspurcado pelos que vieram de fora.

Contra esse preconceito originário e de mão dupla, é possível contrapor que cada cultura grupal é sua própria "jabuticaba", não existindo sociedades nas quais uma fórmula de entendimento possa ser aplicada de forma universal e sem nenhum tipo de mediação. Ao mesmo tempo, a expansão cultural de toda comunidade é permeada por algum nível de relação com as demais culturas, o que permitiria um certo intercâmbio de significados ao compararmos processos de compreensão dos fatores exclusivos e também dos fatores em comum entre grupos culturais que componham um tecido social; no Brasil, buscar uma cultura não-híbrida, que não esteja profundamente marcada 
pelo sinal do negativo, é infrutífero pois "as ambiguidades extirpadas com uma das mãos renascem plantadas por outra" (ARANTES, 1991, p.70). A identidade nacional é a necessidade de uma construção; o lugar do pensamento brasileiro é, por necessidade, um não-lugar, a ausência de um lugar fixo e definido, pelas próprias características de nossa sociedade.

Acompanhando o pensamento de Chauí, a inexistência de tal modelo é indício de que a real dimensão do pensamento "brasileiro" estaria localizada fora de tal amarra. Nenhum modelo de perfeição pode existir para funcionar como coincidência, no máximo como referência, pois a incomensurabilidade entre os padrões em questão produz uma máquina de funcionamento exclusivo, mas cujas forças motrizes podem ser explicadas, ao menos em parte, por fenômenos análogos.

Assim, a pergunta que motivou este texto tem uma não-resposta e esta é a única resposta possível: se é da matriz prática da dialética entre escravismo e lucro, entre Antigo e Novo Regime, entre arcaico e moderno que o pensamento se forma no Brasil, é desta dualidade (não uma oposição, mas um tipo de combinação que preserva os termos sem apagá-los em um terceiro) que a filosofia brasileira pode operar. Trata-se de "pressupor entre os termos que se opõem 'um nexo contraditório que os sintetize numa unidade maior, sem contudo apagar o sistema de ambiguidades de que tal unidade se alimenta'" (ARANTES, 1992, p.74).

O lugar da filosofia brasileira é exatamente o de explorar sua inadequação em relação à chamada filosofia universal, ou colonizadora, sem a negar nem assumi-la tout court. Nossa gramática e discurso surgem da constatação que aqui se escreve uma história peculiar da filosofia, sempre relacionada à história do pensamento ocidental - mas de forma antropofágica.

\section{Referências}

AB'SÁBER, Tales. Brasil: a ausência significante política (uma comunicação). In SAFATLE; Vladimir; TELES, Edson (orgs..) O que resta da ditadura. São Paulo : Boitempo, 2010, pp 187-204

ARANTES, Paulo Eduardo. O novo tempo do mundo e outros estudos sobre a era da emergência. Coleção Estado de Sítio. São Paulo : Boitempo, 2014

. Sentimento da dialética na experiência intelectual brasileira - dialética e dualidade segundo Antônio Candido e Roberto Schwarz. Rio de Janeiro: Paz e Terra, 1992.

Um Departamento Francês de Ultramar: estudos sobre a formação da cultura filosófica uspiana (uma experiência nos anos 60).. Rio de Janeiro: Paz e Terra, 1994. 
- Cruz Costa, Bento Prado Jr e o problema da Filosofia no Brasil - Uma digressão. in ARANTES, Paulo; FAVARETTO, Celso F.; SILVA, Franklin L. et al A Filosofia e seu ensino. São Paulo : EDUC, 1993.

Providências de um crítico literário na periferia do capitalismo. In: ARANTES, Otilia; ARANTES, Paulo. Sentido da Formação: Três estudos sobre Antônio Candido, Gilda de Mello e Souza e Lúcio Costa. Rio de Janeiro, Paz e Terra, 1997. (a)

ARANTES, Otilia; ARANTES, Paulo. O sentido da formação hoje. Praga, São Paulo, número 4, 1997, p. 95 - 109. (b)

CANDIDO, Antônio. Formação da literatura brasileira: momentos decisivos (1750 - 1880). Rio de Janeiro: Ouro sobre Azul, 2013

CHAUI, Marilena. Conformismo e resistência. Escritos de Marilena Chauí v.4. Belo Horizonte : Autêntica, 2014

Apontamentos para uma crítica da Ação Integralista Brasileira. In: Manifestações ideológicas do autoritarismo brasileiro. Belo Horizonte: Autêntica Editora; São Paulo: Editora Fundação Perseu Abramo, 2014.

Sobre a Violência. Escritos de Marilena Chauí v.5. Belo Horizonte : Autêntica, 2017

FAORO, Raymundo. [1958]. Os donos do poder: formação do patronato político brasileiro. São Paulo: Globo, 2012.

FRANCO, Maria Sylvia de Carvalho. Homens livres na ordem escravocrata. São Paulo: Fundação Editora da Unesp, 1997.

As ideias estão no lugar. Cadernos de Debates, n.1. São

Paulo: Brasiliense, 1976

FURTADO, Celso. Formação econômica do Brasil. São Paulo: Companhia Editora Nacional, 1995.

HOLLANDA, Sérgio Buarque de. Raízes do Brasil. São Paulo, Companhia das Letras, 2014.

LEONÍDIO, Adalmir. Carbonários, Maçons, Positivistas e a questão social no Brasil na virada do Século XIX - Fênix - Revista de História e Estudos Culturais Julho/ Agosto/ Setembro de 2008 Vol. 5 Ano $\mathrm{V} \mathrm{n}^{\mathrm{o}} 3$ 
NEGREIROS, Dario. A sombra da Formação. Apresentação. GEE-USP. 07 agosto 2018

NOBRE, Marcos. Da "formação" às "redes": Filosofia e cultura depois da modernização. In: Cadernos de Filosofia Alemã, n.19, jan-jun.2012, pp.13-36.

PRADO JUNIOR, Bento. O problema da Filosofia no Brasil. In Alguns Ensaios: Filosofia, Literatura e Psicanálise. $2^{\mathrm{a}}$ ed. São Paulo, Paz e Terra, 200, p. 153-171

PRADO JUNIOR, Caio. A Revolução Brasileira/ A questão agrária no Brasil. São Paulo : Companhia das Letras, 2014

RIBEIRO, Darcy. O Povo Brasileiro - formação e sentido do Brasil. $3^{\text {a }}$ ed. São Paulo : Global, 2015

SANTIAGO, Homero. O pensamento político de Marilena Chaui: a invenção do método. In: Cadernos espinosanos - Especial Marilena Chaui, n.36, jan-jun 2017, pp.57-87

SCHWARZ, Roberto. Sequências brasileiras: ensaios. São Paulo: Cia das Letras, 1999

. Ao vencedor as batatas. São Paulo: Duas Cidades, 2000.

. “Desapareceu a perspectiva de um progresso que torne o país decente". Folha de S.Paulo, 11 de agosto de 2007 tras, 2012.

Que horas são?: ensaios. São Paulo: Companhia das Le- 